\title{
A Study on the Revitalization of Community Building in Taiwan Based on Qianyang Village
}

\author{
Hongjun $\mathrm{Ou}^{1, *}$
}

\begin{abstract}
${ }^{1}$ Department of Environmental Design, Fuzhou University of International Studies and Trade, Fuzhou, Fujian, China *Corresponding author. Email: 2968981426@qq.com
\end{abstract}

\begin{abstract}
The purpose of this paper is to study the revitalization of Qianyang Village in Jin'an District, Fuzhou City. The paper tries to embed Qianyang Village with the experience of Community Building in Taiwan, and at the same time puts forward sustainable design management strategy. This research is to organize and analyze several successful cases of community building in Taiwan, then transplant them into the community building strategy belonging to Qianyang Village, and combine the local characteristic cultural creativity, and at the same time, refine the residents' requirements and relevant suggestions.
\end{abstract}

\section{Keywords: village revitalization, community building, Qianyang Village}

\section{INTRODUCTION}

Taiwan began to build community in 1993. Its development in the village has been relatively mature, and it is very worthy of the rural development in mainland for reference. The author has been serving in Taiwan industry and academic circles for many years, and has some relevant experience. Many years ago, the author came to Fuzhou to see many villages fade away, and the population of the community continues to drain away. It is hoped that through the investigation and study of this topic, a corresponding rural activation management strategy will be put forward, so that the residents living on the land of Qianyang Village can settle down and live their lives, and at the same time, the community units at the most basic level will be better continued and survived. This paper mainly analyzes several successful cases of community building in Taiwan. They are Yilan Bai Mi Clog Village, Puli Taomi Community in Nantou and Tugou Community Art Museum in Tainan respectively. Finally, the author tries to put forward and summarize a new strategy for community building in Qianyang Village.

\section{Yilan Baimi Clog Village}

\section{A. Location and development of the community}

Baimi Community is in Yongchun Li, Suao Town, Yilan County, near southwest of Fortress Hill, west of the central mountain with three-sided around Xiaomao Mountain, Baishi Mountain, Houyi Mountain, east of the Pacific Ocean. The coastline is up to three kilometers away, South border with Nan'ao. The name of Baimi Clog Village does not mean that all community residents have worked like this. Rather, it is a community atmosphere formed on the basis of achievements in the regeneration of major abandoned spaces and public construction and the concept of clog village.

In 1998, the community organized the Baimi Community Cooperative, which is open for business, to make public property with all residents' shares, and to prevent resources from falling into the pocket of fewer people. In 1999, the residents of the community abandoned the "Taifei" dormitory on the roadside for reorganization ("Fig. 1").

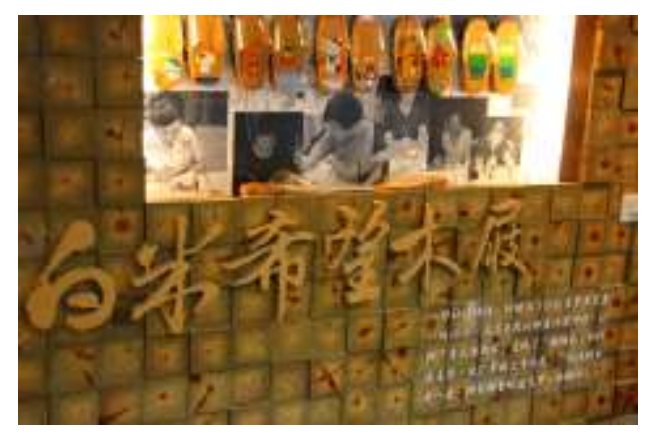

Fig. 1. Illustration of the Baimi Clog Museum (photo taken from the web).

After cleaning the weeds around the building and the house smelly fertilizer and the moldy waste gas, the community has one more public place and attraction. Community residents refer to the cubicle wall through the moving line, production, processing, display, DIY, sales in series, to form an organic link. This space has become the main location of the current clog exhibition 
hall. In 2000, the idle and abandoned space around the lease was integrated into the clog neighborhood. In 2001 and 2003, the old hostel was combined with the abandoned nursery to become Clog One, Clog Two and Clog Three. Then the old hostel was bought and expanded to three stairs by bank loan. After two years of expansion and renovation, the new one was completed in the summer of 2006. Since then, the Baimi Community Development Association has completed the transformation of community space in the Baimi Community, and has re-positioned the function of abandoned space in the community. With a lot of tourists visiting the community, it has formed a lot of pressure on the community factories. It can also be found that the community factories carry out autonomous greening and beautification, and the driving lanes are adjusted more friendly. The image of Baimi Clog changed from "stone factory" to "clog village". The process seems to be mild and gradual, but it is a way to create a win-win, strong and powerful resistance.

From the perspective of the cultural industry, the Baimi Community Development Association has activated several abandoned spaces in the community into recreational spaces, and the surrounding factories are also equipped to improve the pollution source. There are also local specialties nearby, such as the shell shop and grandma's grocery store. Of course, many snack stalls have also been added. There are a few dozen community residents work here to form an industrial system and an industrial culture. The abandoned space can be reborn quickly in the community. It is no longer a simple industrial land space, but a life with local cultural characteristics space.

\section{B. Community building and museum building}

The Baimi community industry is basically an experience derived from the spirit of the overall construction of the community. The promotion strategy of its wooden puppet industry is not a corporate, professional, and alienated operation, but instead demands a localized and participatory consumption model. The community promotes an "experienced" consumption environment. The vast majority of sales are made by visitors after purchasing and interacting (including participating in implementation or part of the operation). And for this kind of experience economy, the most important thing is the atmosphere of the building, and the spirit of the charisma. Through the local experience, the distance between visitors and products is closer. This is an important feature of community construction to promote community industry. In terms of the relationship between the exhibition hall, the viewer and the product, such characteristics are equally important and critical in the operation of the museum.

\section{TAOMI ECOLOGICAL CULTURE VILLAGE}

\section{A. Geographic location}

Located in the north-central part of Nantou County, Puli Town has a fertile basin plain and unique climatic condition, making it an important flower and fruit producing area in Taiwan. This case covers the Taomi Community in Puli Town, Nantou County, about five kilometers south-west of Puli Town, covering an area of about 18 square kilometers. Taomi is located on a hill of about 430 to 800 meters above sea level. It is the area with the most abundant ecological diversity. It is a low-developed traditional small mountain village.

\section{B. Community development after the "9.21 Earthquake"}

Though the "9.21 Earthquake" in 1999 devastated the Taomi Community, it brought opportunities for community reconstruction. At that time, Taomi had 369 households, among them, 168 households were fully devastated and 60 households were half devastated. The disaster was very serious. After the earthquake, the Soil and Water Conservation Bureau, the county government and the town government invested a considerable amount of funds for the construction of soil and water conservation. In January of the following year, a community reconstruction committee was reorganized with the assistance of Wang Yuanshan, a research fellow in the New Hometown Culture and Education Foundation, and Lin Zhensheng, a planner in the Puli Studio of the Urban Reform Organization. The committee formed four reconstruction groups: research and development group, space settlement group, industry group and water protection group. And with the establishment of the reconstruction committee, people with lofty ideals can show their ambitions in the community. And as the residents actively participate in the reconstruction work, they quickly change the longterm indifferent attitude towards public affairs. The work has also drawn close to the feelings of the residents of the Taomi community, and built a community that helps and cares each other. On September 20, 2001, on the eve of the second anniversary of the "921 Earthquake", Philips held a "New Hope for Home Building" event in Taipei. It announced that it would sponsor the eco-education work of the New Home Culture and Education Foundation in Taomi, Puli Town. It also invited President Li Yuanzhe, Director Yan Rende of the Special Biological Conservation Center of the Agricultural Commission, and President Ze Wenbo of Philips of Taiwan. Together, they issued certificates to nine Taomi ambassadors who passed the certification, and encouraged Taomi township's efforts after the disaster. Li Yuanzhe said that the transformation of the rural economy must be carried out on the premise of respecting the ecology, and Taomi Ecological Village is 
the implementation of this concept, which worthy of social affirmation ("Fig. 2").

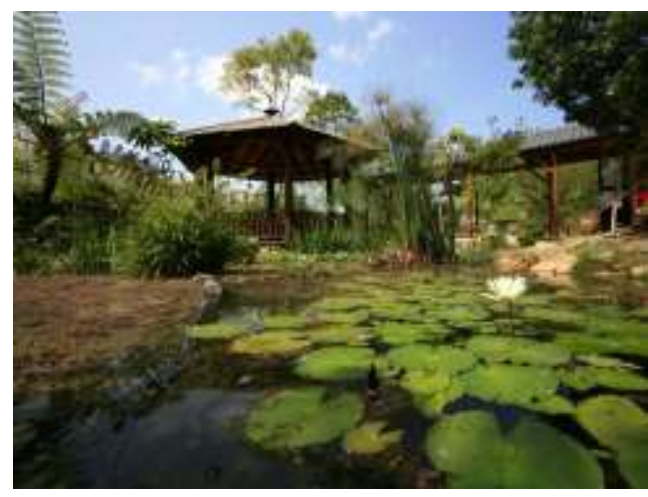

Fig. 2. Taomi Eco-Culture Village Park (image taken from the Internet).

\section{Tugou COMmunity ART MUSEUm IN TAINAN}

\section{A. The context of community construction}

Tugou Village (Li), Houbi District, Tainan City is a mile under the jurisdiction of Houbi District, Tainan City, Taiwan. The village located in the remote rural area of the northernmost part of Tainan City. The economy of the village is dominated by rice, cantaloupe and lotus. Before 2002, Tugou had not yet promoted community work, and the backward countryside was treated as a garbage village. The community was left with only dilapidated houses, the elderly and the last buffalo. Tugou people do not dare to say that they live in the ditch, thus the helplessness of the place can be imagined. Residents in the community rise the concept to change and set up the Tugou Rural Cultural Construction Association in Tainan. The association takes the last buffalo in the community as a community-building spiritual symbol, and compares the hard-working spirit of the buffalo to the group of Tugou people who are willing to contribute to their hometown. The association also encourages residents to pick up hoe to clean their homes, trying to subvert the sad impression of the decline of rural areas, barren farmland, and industry decay.

At the end of 2002, Tugou took art as the direction of community management, but the word "art" is often inexplicable and can only be accumulated by attempts. In 2005, Tainan Art University went to Tugou. The collision and dialogue between young graduate students and 70-year-old farmers combined art with local life and culture, and started the process of art rural construction. In 2006, the art was introduced into the concept of life (rural), advocated that "art is life, and life is art". It attempted to turn "hard-working farmers into elegant farmers", and pondered the possibility of another combination of art and rural management. After a decade of experience, in 2012, the first art museum in Taiwan was built - Tugou Rural Art Museum under the name of the village. The museum used art as a medium for the residents to convey their feelings and ethics to the land, broke the form of physical art works and pavilions, and treated the houses as exhibition halls, farmland as canvases, agricultural products as works of art, and farmers as artists ("Fig. 3").

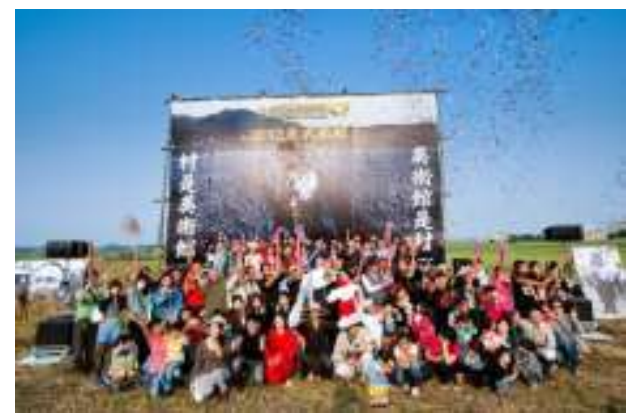

Fig. 3. Opening of Tugou Rural Art Museum (photo taken from the Internet).

\section{B. The concept of community art}

Local aesthetics is a re-gazing of the living world. Finding the local unique emotions, memories, production scenery, and local skills from the living world refers to a rediscovery process that stands in the present. In 1983, the experience of the Japanese Community Art Museum began to flourish in the community. In 2002, the concept of local cultural museum was put forward and the community cultural relic museum was set up. The Tugou Rural Art Museum is established not for the purpose of building an art museum. Instead, it has accumulated and promoted year by year with the concept of the art circle, and has re-examined the aesthetics of land with the rural art museum. It is a new form of constructing a community management model. The foundation of Tugou Rural Art Museum is in the countryside. Faced with the imbalance of rural production and sales structure and the urbanization phenomenon of population migration, localities will regain the right of interpretation. Recalling the memories of the ancestors and actively creating the conversion to meet current social needs are what the community art that Tugou Village has been striving for decades.

\section{The difficulties in the building of the community in Taiwan}

The community building in the past ten years has always emphasized the investment in the "public domain" and the lack of in-depth thinking and attention to the "private domain". In the second decade, we may try to use the concept of "private domain vs. public 
domain" to cultivate people's democratic literacy, learn to communicate with people, understand each other, respect others. The concept is used as the basic attitude to participate in public affairs. Then, people should learn to observe the community, observe the society, and form a close link among individual life, community life and social change to explore the real problems, needs and development direction of the community. In addition, the traditional Confucian culture emphasizes that the construction process of a perfect world includes "self-cultivation, family-building, state governance and world peace". With this familiar concept, people can put community building into "self-cultivation", "familybuilding", "state governance" and "world peace", so as to make up for the long-lost block of Taiwanese culture. The traditional Confucian culture also attempts to connect (inside) the "private sphere" of individuals and families and connect (outside) the "public domain" of the region, society, and the world in order to break through communities in the past and create "small nations and residents, and being concerned only for communities (local public domain)". At the same time, "social creation" should contain not only the "community building", but also the "social transformation" of the cultural civic significance.

Although the overall construction of the community has taken more than ten years, it is found that there is a "private vs. public domain" fault between "familybuilding" and "community creation". It seems that people who come out to do community building have to sacrifice for others and for public affairs. Therefore, community building must proceed from the concept of "community home". It is expected that in the process of operation, community organizations and residents will expand the imagination of "home" into "family" and directly link up with the "community", letting the integration of benefiting themselves and benefiting others. In order to cultivate more community citizens and create a "common community" that belongs to everyone, it is necessary to make "social creation" a part of daily life and let care and participation in "home transformation" become the values and habits that should be taken for granted.

\section{CONCLUSION}

After more than 20 years of community building in Taiwan, what can be seen is that the residents' sense of identity to their community's land. Referring to the Tugou community mentioned in this article, a group of graduate students take the initiative to enter the community, through the aesthetic environment to introduce art. And the art creation itself as "factor", from the environment green beautification, the space transformation, the activation or the idle space reuse, is the improvement or the transformation of the living environment. This is because community building as a whole is a dynamic process of human beings itself.
Since it is a dynamic state, the environmental transformation is not made for the single purpose of the environment. It should be regarded as a dynamic state, which results in a dynamic logic. In this logic, environmental transformation is a transitional stage, which is used as a cut-in point in the pre-stage and a public domain in the post-stage. With this kind of thinking logic, the issue of environmental transformation evolved from a topic to a strategy. This more oriented and more strategic way of thinking about social creation can be said to be the most distinctive and interesting feature of community building.

Environmental transformation is a way of approaching, but it is equally important in itself. After initiating community discussions, designing operating methods for the source of the problem, and appropriately mobilizing community residents to participate in the division of labor, it is also very important to do a good job in environmental reconstruction itself. Because this has two functions, one is to let the participants get a sense of accomplishment, appreciate the value and joy of participating in the community's public affairs, and then be willing to continue to participate. Another is to let the community residents realize that the improvement of environment and space really brings a better living environment/ way for everyone, and then understands the meaning and importance of community public affairs, from indifference to attention (even passive support is a kind of progress); so there is an important transformation.

There are two axes of evolution, one is from the unconsciousness to the consciousness to the attention to the action, and the other is from the environmental issue to the public nature of the environment to the formation of the community public domain. When these two axes interact, they interweave into a new community. In this context, in addition to the private sphere of life, there are also public domain norms, so we can further operate more challenging areas such as community conventions, eco-villages, cultural reconstruction, and so on. That is to say, the possibility of a new community development arises from the formation of the community public domain. The formation of the public domain is due to the start of environmental transformation and an effective environmental transformation action. An effective environmental transformation action is rooted in a true understanding of the problems and is intertwined with each other, forming a dynamic social operation strategy. To sum up, it comes down to a research framework of community space architecture, which is summarized as follows ("Fig. 4"). 


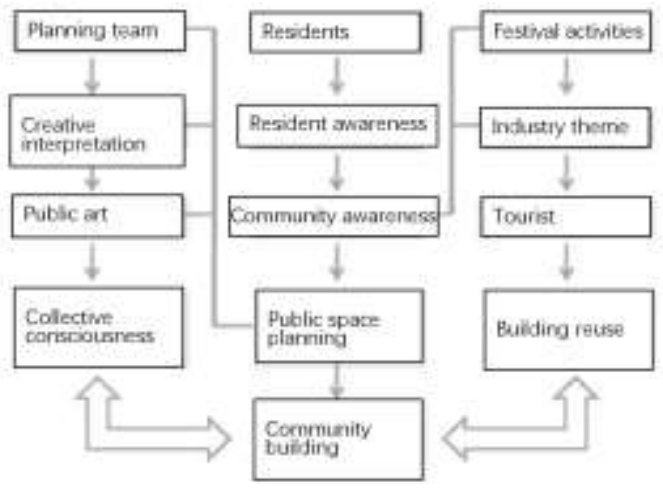

Fig. 4. A schematic diagram of a new strategy for community building in Qianyang Village (self-drawn by the author).

Here the author tries to propose communitybuilding strategies for Qianyang Village. The first strategy is that the planning team should mainly focus on artists to carry out resident creation plans, which may take several years. And its main purpose is to revitalize the former idle space (buildings, open spaces, roads) of Yangcun. Beautifying the community environment through art creation can also give people the opportunity to participate. The second strategy is that the public space in the village is designed by a professional team (Fuzhou University of International Studies and Trade-Department of Environmental Design) to lead the residents to design, and the community residents should be mobilized to participate in the work to get a sense of community. 3. Organizing the Qianyang Village Industrial Culture and Sightseeing Festival to attract tourists. The main purpose of the event is to attract tourists.

This study also suggests that Qianyang Village can integrate cultural resources with local activities, promote local cultural legends through festival activities, make local characteristic management and economic industry present a win-win situation, so as to enhance local residents' centripetal force. In the process, we can combine the concept of eco-cultural tourism with local organizations to create employment opportunities for the people at the grass-roots level to improve the added value of eco-tourism industry. It is suggested to integrate the special landscape and folkcustom activities in Qianyang Village to form an ecovillage strategy concept with sustainable development.

\section{References}

[1] Huang Junhao. Seeing Art in Rural Areas-Experience of Community Art in Tainan Tugou Rural Areas [D]. Institute of Architectural Art, Tainan University of Art, 2001. (in Chinese)

[2] Cai Huipeng. A Study on the Influence of Rural Public Art and Community Development: Taking Tugou District of Tainan City as an Example [D]. Institute of Cultural and Creative Management, Nanhua University, 2016. (in Chinese)
[3] Guo Fangyu. Artistic Disturbance and Community Agglomeration: A Case Study of Tainan Backwall Tugou Rura and East Shandong Original Community [D]. Institute of Architectural Design, Success University, 2018. (in Chinese)

[4] Liao Yimei. The Creative Relationship of Art in the Public Field: A Perspective of Taiwan's Environmental Movement [D] Institute of Arts and Administration, Taipei University of Arts, 2006. (in Chinese)

[5] Ma-Li Wu. Art and the Public Field: Art Into the Community [M]. Taipei: Far Stream, 2007. (in Chinese)

[6] Diana. Diana Crane, translated by Zhang Xinlong. The Transformation of Avant-garde Art. [M]. Taipei: Far Stream, 1996. (in Chinese)

[7] Suzanne Lacy, translated by Wu Mari, et al. Metrics: A New Type of Public Art. [M]

[8] Koroche. Dr. Craig Dreeszen, Editor-in-Chief, translated by Gui Yawen, et al. Community Art Management [M]

[9] Yamazaki Ryo, translated by Chuang Ya-hsiu. Community design: Rethinking the definition of 'community', not only the design of space, but also the design of 'human-to-human connection' [M] Taipei: Facebook, 2015. (in Chinese)

[10] Willie. Written by William E. Doll, translated by Wu Mali. "The Art of Objects (OBJEKTKUNST)." [M] Taipei: Far Stream, 1991. (in Chinese) 